Fecha de recepción: septiembre 2013

Fecha de aceptación: abril 2014

Versión final: septiembre 2015

\section{Apuntes sobre el rol del audiovisual en una genealogía materialista de la representación}

Fernando Mazás *

Resumen: El problema central del artículo es la conformación lingüística del signo audiovisual en el contexto de un "diálogo imaginario" entre las perspectivas que Pier Paolo Pasolini y Gilles Deleuze, en sus escritos Empirismo Herético y La Imagen-Tiempo respectivamente, desarrollan sobre dicha temática.

En primer lugar, lo que el filósofo francés reivindica sobre la teoría de Pasolini es que (a diferencia de Metz, Eco, Garroni y otros semiólogos contemporáneos de la década de '60, quienes han atacado al autor acusándolo de falta de profesionalismo e ingenuidad semiótica) la narración no es un dato manifiesto de las imágenes cinematográficas en general, sino que fue históricamente adquirida. Esto se debe a que precisamente ambos autores (y esta tal vez sea su coincidencia teórica central) consideran que la imagen cinematográfica no puede ser asimilada ni reducida a un enunciado.

Es por eso que teniendo en cuenta que los adelantos tecnológicos y la proliferación de formatos, géneros, canales de producción y distribución proponen desafíos analíticos cada vez más numerosos y profundos, recuperar y analizar a fondo las consecuencias de esta perspectiva teórica, puede generar un gran aporte en los estudios contemporáneos de los lenguajes audiovisuales.

Palabras clave: audio-visual - cine - Félix Guatari - flujos - Gilles Deleuze - Henri Bergson - neo-materialismo - Pier Paolo Pasolini - postestructuralismo - representación - Semiótica - significación - subjetividad.

[Resúmenes en inglés y portugués en la página 77]

${ }^{(*)}$ Licenciado en Cinematografía (orientación dirección, cuya tesis de grado está en proceso de edición) por la Universidad del Cine, en la cual dicta clases en las cátedras de Semiología y Semiótica del Cine.

No es ninguna novedad decir que Pier Paolo Pasolini fue una de las figuras intelectuales más destacadas de Europa de la posguerra. Su voluntad polémica y permanente confrontación con el poder y con los discursos establecidos fueron expresadas en una prolífica carrera como artista multimedia que abarcó desde la poesía dialectal hasta el cine, el artículo periodístico, el ensayo crítico, hasta la novela y el teatro. Pero por sobre toda las cosas, fue un gran autor, pero no tanto en el sentido tradicional de la palabra, sino en el 
que Michel Foucault, en su ensayo ¿Qué es un autor? (Adams y Searle, 1966.pp. 138-148), le da a esta figura; un verdadero iniciador de prácticas discursivas, un espacio que surge en un momento histórico determinado, el cual ejerce una profunda influencia, donde se produce un diálogo, un combate, una negociación y contaminación (para utilizar un término de su vocabulario) entre discursos ideológicos, posicionamientos estéticos y tradiciones culturales.

A través de su tan particular modo de hacer cine, Pasolini fue uno de los autores que ha cuestionado y desafiado de forma más radical y profunda a las convenciones históricas de las técnicas audiovisuales, a las que siempre consideró una práctica discursiva cuyas potencias nunca se cansó de explorar. Lo que Pasolini simbólicamente significa como autor; una orgía de tradiciones culturales que van desde Dante hasta la borgata romana, pasando por el marxismo, el psicoanálisis y la religión católica. Este apasionado y perturbador encuentro entre referentes culturales, a primera vista tan diversos y distantes, producen, a través del acto poético, una crisis de sentido que no solamente nos interroga por la naturaleza del lenguaje cinematográfico y por el rol social de director de cine, sino que por extensión llega a cuestionar los presupuestos ideológicos que soportan a la cultura dominante y a nuestra identidad como sujetos, invitándonos a encontrar nuevos caminos y tendencias que nos ayuden a configurar ese ámbito al que comúnmente llamamos realidad.

Dentro de este contexto la propuesta del siguiente artículo será la de analizar la progresión y mutaciones específicas que informan la primera parte de la filmografía del director italiano como modelo de autor-función. En un mundo como el de hoy donde la proliferación de nuevas tecnologías, medios de producción y canales de exhibición es más efervescente y frenética que nunca, tal vez, como dice Foucault, ha llegado la hora de estudiar no sólo el valor expresivo y las transformaciones formales del discurso, sino su modo de existencia: las modificaciones y variaciones dentro de cualquier cultura, de los modos de circulación, valorización, atribución y apropiación. En parte a expensas de los temas y conceptos que un autor ubica en su obra, el "autor-función" podría también revelar la manera en que el discurso es articulado sobre la base de las relaciones sociales. Es en este sentido que el modelo autoral de Pasolini resulta absolutamente contemporáneo.

\section{Comienzos: relación con el neorrealismo}

A pesar de fugaces colaboraciones como consultor de guiones durante la década del cincuenta, Pier Paolo Pasolini comienza su carrera como realizador con el estreno de Accatone, su primer film, en el año 1961, diez años después del auge del Neorrealismo. De todos modos, con esta escuela cinematográfica mantuvo un vínculo estrecho y complejo que influyó en toda su carrera. Por un lado tanto el director italiano como la escuela cinematográfica de la posguerra tenían una pasión común que era la voluntad de representar la realidad en su esencia más íntima, realidad que era ocultada por discursos ideológicos perversos que buscaban distorsionarla. Por lo tanto, los directores que formaban parte del 
neorrealismo sabían que para plasmar el nuevo proyecto nacional en una Italia diezmada que estaba resurgiendo de las cenizas de la guerra, no bastaba con la creación de nuevos argumentos sino que también sería necesario una nueva poética que en su estilo expresara este nuevo posicionamiento ideológico capaz de representar de un modo fiel y confiable aspectos de la realidad que tradicionalmente habían sido dejados de lado. Según la concepción tradicional de la crítica cinematográfica, el Neorrealismo pondrá el acento en el hecho de que la realidad es un fenómeno que ontológicamente existe fuera de cualquier discurso y debe ser introducido en el film con la menor cantidad de mediaciones posibles. Propondrá un discurso donde el ideal estético será un cine directo que tienda hacia la objetividad total y que logre, a través de los medios más austeros y despojados de artificios, captar el momento cuando la realidad se pone de manifiesto en todo su espectro.

La semiótica del cine que se comenzaba a popularizar en la década del '60 junto con la teoría cinematográfica realista de Bazin, dividiría el material cinematográfico en dos categorías: primero el material pro-fílmico, eventos y objetos que aparecían delante de la cámara, y material fílmico, eventos y objetos que aparecían en la pantalla del cine previamente capturados por la cámara. La principal razón por la cual el Neorrealismo era considerado un nuevo realismo consistía en que, en su afán de aprehender la realidad externa (instancia pro-fílmica) con la mayor fidelidad posible, este estilo de representación había rechazado muchas de las principales convenciones narrativas y estilísticas más comunes del realismo clásico. Los argumentos artificiosos y melodramáticos ambientados en ampulosos decorados típicos de las puestas en escena de los sets de estudio, la iluminación pictórica y recargada, el estilo de interpretación virtuoso de los actores de método y la piezas de música incidental ejecutada por grandes orquestas fueron dejadas de lado en pos de un cine de bajo presupuesto filmado casi enteramente en escenarios naturales y con actores no profesionales. Según Bazin, el plano secuencia (secuencia de larga duración sin cortes donde la acción registrada se desarrolla en tiempo real) era el rasgo técnico estilístico distintivo de este movimiento. Se creía que el plano secuencia no solamente presentaba el real pro-fílmico como ocurría sino que también se abstenía de agregarle un valor dramático artificial. Las narrativas "desdramatizadas" eran características de los films neorrealistas. Nada era particularmente remarcado ni tampoco eran efectuadas conexiones precisas. En palabras de Roberto Rosellini: “Las cosas son, para qué manipularlas". En vez de imponer un orden al mundo, el realizador simplemente reflejaba un orden ya dado. La manipulación y la falsificación de la realidad en artificios narrativos era asociada con el cine bajo el fascismo, un cine de géneros modelados en Hollywood. Esta manipulación y falsificación era también asociada con la cultura de la burguesía italiana cuya cultura literaria estaba dirigida a una elite y no al pueblo. Este compromiso con la realidad pro-fílmica, queriendo reproducir la realidad enteramente en la pantalla, confiando en el poder bruto de la realidad por sobre cualquier figura narrativa, estilo o lenguaje, fue también interpretado muy frecuentemente en términos políticos e ideológicos. El periodo del Neorrealismo era también considerado el período de la resistencia cultural italiana, a partir de la cual una nueva, popular, democrática y antifascista Italia iba tomando forma. La representación de esa realidad era pensada como un acto político progresista. 


\section{Realidad, esteticismo y escritura}

Los primeros cuatro films de Pasolini, Accatone (1961), Mamma Roma (1962), La Ricotta (1963) y Il Vangelo secondo Matteo (1964) pertenecen a lo que el propio director denominaría su "fase nacional popular gramsciana" y por lo tanto eran los que estaban más cerca de las intenciones políticas del neorrealismo, a pesar de que estilísticamente tenían marcadas diferencias. La tendencia antiliteraria característica del Neorrealismo estaba ausente de la obra de Pasolini. El realismo del Neorrealismo fue en parte un intento de desligar al cine de lo literario y por lo tanto del mundo burgués y de sus convenciones estilísticas estigmatizadas como falsas. El objetivo era ir en dirección a una realidad popular, verdadera y nacional. Con este movimiento de resistencia no solamente las instituciones democráticas eran puestas en su lugar sino que también aparecerían por primera vez una verdadera cultura popular. El Neorrealismo retrataría el comienzo de la democratización de Italia y su unificación "nacional-popular". Para muchos en aquella época el sueño "gramsciano" estaba por convertirse en realidad. En cambio, el cine de Pasolini se ocupa de la relación entre las palabras y las imágenes, el lenguaje y el film, el arte y la realidad. Su estilo, a diferencia de los neorrealistas, no tenía nada que ver con el Naturalismo. Mientras ellos estaban casados con el plano-secuencia que daba una sensación de plenitud espacio temporal, sus films estaban basados en la fragmentación espacial en encuadres de diversas perspectivas y la discontinuidad de una construcción artificial del tiempo mediante la edición. El impulso neorrealista era documental mientras que el suyo, artificioso. Ellos confiaban en la espontaneidad, la intuición y las contingencias, él confiaba en el guión y la meticulosa planificación previa. Si Bazin estaba en lo cierto al creer que el sentido narrativo de los films neorrealistas siempre venía a posteriori, en los films de Pasolini el sentido existía a priori. En sus films la realidad no era encontrada o revelada, sino creada. Muy poco era derivado al azar o a la contingencia. La impresión de realidad no se hacía sentir fácilmente. Las analogías en estos films no eran encontradas en la naturaleza sino formadas en el arte, cuya insistente presencia en toda su filmografía se manifiesta a través de citas tanto pictóricas como musicales y literarias. La realidad también es citada, aparece como algo textual. Si los films neorrealistas contienen instancias reales concretas, los de Pasolini contienen un pastiche de citas culturales altamente organizado, subrayando su artificiosidad y su esteticismo. Pasolini fue, preponderantemente, un escritor que, a través del lenguaje y la literatura, buscó y manufacturó la realidad. La tendencia del Neorrelismo fue, por el contrario, enteramente antiliteraria. Buscaba la especificidad del cine en contra de la literatura y hasta del lenguaje, teniendo en cuenta que la presentación del momento real habitualmente aparecía como "borramiento" de la escritura.

Sin embargo, existe en la obra de Pasolini el mismo sentido de que el cine pertenece a la realidad mientras que el lenguaje escrito-hablado se distanciaba de ella. Al igual que muchos otros intelectuales y escritores italianos de la posguerra, Pasolini quería encontrar lo real, y al igual que ellos, encontraba el lenguaje oral-escrito como un instrumento inadecuado e imposible. El cine, felizmente, no parecía ser un lenguaje como el oral escrito, sino más primitivo y por ende menos culturizado, burgués y literario. Por lo tanto era un lenguaje más real. Por lo menos en el cine la realidad puede ser transcripta de forma más directa, liberándose de la sustitución simbólica realizada por las palabras. Este sueño no 
era fundamentalmente, o por lo menos en su intención, muy diferente al sueño neorrealista (Baranski, 1999, pp. 164-179). Según el autor, una diferencia substancial entre la estructura de la lengua oral-escrita y la del cine es que esta última se presenta como transnacional y transclasista. Por ende: "Prefigura una situación socio-lingüística posible en un mundo que se ha vuelto tendenciosamente unitario por la industrialización total y por la nivelación que de esta resultaría, implicando la desaparición de las tradiciones particularistas nacionales" (Pasolini, 1982). Una lengua que se funda en la reproducción audiovisual al igual que sus estructuras narrativas que expresan la realidad a través de la realidad, no puede poseer estructuras estrictamente homólogas a la sociedad histórica en la que determinado film fue creado, sino que estas estructuras son idénticas a las de cualquier país en el que el film se proyecte. La utilización de un medio que le permita al autor la posibilidad de expresarse sin por ello contribuir como efecto colateral en el proceso de homologación que traen aparejadas las lenguas nacionales es lo que termina de convencer a Pasolini de embarcarse en la actividad cinematográfica. En sus palabras es el abandono de una Italia "maldita" (homologada por el consumismo pequeñoburgués) por una Italia "transnacional" es lo que le permite seguir viviendo de acuerdo con su propia filosofía evitando caer en profundas contradicciones.

\section{Contexto histórico de Italia de la posguerra: el genocidio cultural}

A partir de comienzos de la década del '50 y a consecuencia del fin de la segunda guerra y la caída del fascismo, una Italia devastada comienza su proceso de reconstrucción. Era necesario salir de la pobreza extrema en la que la nación había quedado sumida. Fue entonces que a partir de una agresiva política de fomento de la industria y del desarrollo del comercio se produjo lo que luego se daría a llamar el "Milagro económico" de Italia de la posguerra. Durante esta década todos los índices económicos comenzaron a subir de manera vertiginosa. El índice de desempleo se redujo considerablemente y el confort en los hogares se incrementó. El proceso de industrialización comenzó desde el norte y se fue expandiendo hacia el centro hasta la capital finalmente fue conquistando el sur, la región mas "atrasada" de Italia donde en su gran mayoría aún se seguían manteniendo las tradiciones ancestrales. ${ }^{1}$ A pesar del desarrollo y aparente crecimiento en todos sus índices, Pasolini cree que esta nueva etapa capitalista que atraviesa su país respondía a una ambición descontextualizada y colonizadora de instaurar el "Sueño americano" en Italia. Luego la preponderancia del consumo y la creación de valores e instituciones que lo fomenten y lo sostengan. La familia, la escuela y los medio masivos de comunicación estaban ahora destinados por sobre todas las cosas a la estimulación del consumo. Este nuevo régimen era en realidad para el autor italiano una continuación disfrazada del fascismo que en su versión paleocapitalista y clerical-fascista democristiana, estaba evolucionando hacia su forma más sofisticada de poder: el neocapitalismo consumista. Esta era la tercera etapa de un proceso que encaminaría a Italia a un estadio de profundo deterioro cultural: “... Primero el fascismo; luego un régimen clerical-fascista fingidamente democrático y que por último han aceptado la nueva forma del poder, el poder del consumismo, la última de 
las ruinas, la ruina de las ruinas" (Pasolini, 1997).

Esta última etapa del proceso genera también dos fenómenos complementarios sobre los cuales el autor italiano vuelve incansablemente en sus escritos y que afectan directamente a la identidad nacional: la homologación y la entropía cultural pequeño burguesa. De acuerdo con Silvestra Mariniello el término entropía procede del alemán entropie, término propuesto por el físico alemán R. J. Clausius en 1850 y retomado por analogía con el término energía del griego entropé, que significa "cambio de disposición", "acción de volver en sí mismo". Según el diccionario de la Real Academia Española la entropía es además una "función termodinámica que es una medida de la parte no utilizable de la energía contenida en un sistema" (Mariniello, 1999). En el artículo “Il PCI ai giovani!” Pasolini expresa claramente su preocupación por las consecuencias que sufriría su país a partir del avance de la sociedad de consumo:

...la burguesía está por triunfar, está por convertir en burgueses a los operarios, por un lado, y a los campesinos ex coloniales, por otro. En resumen, a través del neocapitalismo, la burguesía está por tornarse la propia condición humana. Quien nació en el cuadro de esta entropía, no puede de manera alguna, metafísicamente, colocarse fuera de ella. Se acabó. (Pasolini, 1982).

Estos dos fenómenos son los pilares de un proceso al que Pasolini denomina genocidio cultural. A través de este proceso los valores de la sociedad de consumo van violentamente transformando y sustituyendo los valores de la cultura tradicional en pos de una vida con mayor confort instituyendo de este modo una única vertiente histórica y cultural:

...considero que la destrucción y sustitución de valores en la sociedad italiana actual lleva, aunque no sea a través de sacrificios y fusilamientos masivos, a la supresión de grandes zonas de la misma sociedad... amplios estratos que quedarán fuera de la historia (historia de dominio burgués y de revolución burguesa) sufrieron este genocidio, o sea, esta asimilación al estilo y a la calidad de vida de la burguesía (Pasolini, 1993).

Pero también remarca un hecho importante; el estilo y la metodología del genocidio al que se refiere Pasolini tiene características distintas al descrito por Marx ya que en su época la imposición violenta de la conquista había madurado en una técnica cuyos medios eran más sutiles, hábiles y complejos.

\section{Antropología y lenguaje}

Estas observaciones que Pasolini realiza sobre la lengua italiana oral-escrita son el reflejo de un profundo cambio antropológico que la Italia de la posguerra comenzaría a sufrir a partir de la irrupción de la cultura neocapitalista correspondiente al ya mencionado 
"Milagro Económico" de la década del cincuenta y sesenta donde las condiciones de vida de los ciudadanos cambiarían abruptamente. Por ende, y a contramano de la tendencia estructuralista, en pleno auge en el análisis cultural de aquel momento, Pasolini propone que la lengua italiana (a diferencia de la francesa) no reposa sobre una estructura estable sino que es una estructura que, en permanente ebullición y metamorfosis, quiere ser otra estructura. Esta hipótesis no sólo se aplica estrictamente a la lengua sino que también tiene una connotación sociológica ya que para el autor por el solo hecho de ser italiano le impide tener una mentalidad estructuralista:

Vivo en un cuadro de un orden establecido tan idiota como precario. No encuentro a mi alrededor ninguna certeza social. Por ejemplo, las estructuras fónicas y gramaticales de mi lengua son inestables, arbitrarias, infinitamente mutables, infinitamente perturbadas por múltiples formas concurrentes, y reunidas apenas por una voluntad organizadora o ficticia y autoritaria (Pasolini, 1982).

Esta crítica al estructuralismo, surgida de la observación de la realidad de la Italia de la posguerra en la que el propio autor habitaba, lo lleva también a repasar la fervorosa polémica que aconteció en el campo de la antropología entre la postura estructural de LeviStrauss y la postura empirista de Gurvitch. La antropología estructural de Levi-Strauss no le terminaba de convencer ya que la consideraba demasiado idealista y nominalista y en este tipo de análisis se corre "el peligro de reemplazar a la realidad por su modelo". En el otro polo, la visión de Gurvitch tampoco le resulta del todo satisfactoria porque la encuentra demasiado basada en una concepción ontológica e irreductible, que considera demasiados aspectos como "naturales" dejando fuera del análisis la existencia de sistemas y la participación del hombre en la creación y modificación de los mismos. Finalmente, con respecto a este punto, Pasolini toma partido por dos perspectivas ideológicas: por un lado, adhiere a las críticas que los sociólogos norteamericanos le hacen al estructuralismo por las cuales, sin caer en la crítica radical de los empiristas proponiendo una ontología de la realidad, sugieren reemplazar la concepción de estructura monolítica y meta-histórica de la antropología estructural, por una estructura dinámica que, articulada por los movimientos de "estructuración, desestructuración y reestructuración", redefine a la estructura como proceso; y por el otro, expone su necesidad de recuperar al marxismo como la única ideología que lo protege contra la pérdida de la realidad. En resumen, el racionalismo estático propuesto por el estructuralismo presenta una monovalencia de la realidad; en el otro extremo, el racionalismo dinámico de la antropología empirista introduciría una polivalencia. Finalmente, el racionalismo dialéctico presenta una estructura estratificada de la realidad, que representa al punto medio deseado.

No obstante, a pesar de que Pasolini buscó siempre la realidad como un estadio previo al lenguaje, solamente pudo aproximarse a ella por medios lingüísticos. Esta paradoja, con la que Pasolini ya se confrontaba en sus épocas de poeta, no fue resuelta al mudarse al medio del cine, sino que fue duplicada. El cine le pudo haber ofrecido un contacto más directo con la realidad que tenía a través de la literatura, pero de todos modos le demandaba un camino discursivo para arribar a ésta. Esta tensión está muy presente en su teoría cine- 
matográfica, realizada en su mayoría a mediados de la década del sesenta y compilada en Empirismo Erético. A pesar de realizar referencias explícitas a la semiología de Ferdinand de Saussure, uno de los presupuestos teóricos fundamentales del estructuralismo, movimiento filosófico imperante de la época, el principal referente de la teoría cinematográfica de Pasolini (especialmente del célebre artículo de 1965, El cine de poesía) sería la teoría lingüística de Benedetto Croce. Mientras que Saussure propone al lenguaje como un sistema cerrado y sincrónico donde los signos se relacionan entre sí a partir de funciones regidas por los principios de repetición y diferencia, y que a su vez cada signo mantiene una relación de autonomía y arbitrariedad con respecto a su referente real, Croce en cambio, concibe al lenguaje de forma diacrónica, como una instancia lírico-expresiva donde el signo, en estrecha relación con el referente, se modifica de forma constante sufriendo una evolución dinámica donde se recrean recíprocamente.

Para Saussure el lenguaje es un acontecimiento preponderantemente racional, donde cada signo representa un concepto. Para Croce, el lenguaje es principalmente un hecho estético donde cada signo representa la expresión de una intuición. Visto de esta manera, la perspectiva de Croce estaría mucho más emparentada con el análisis de la imagen y del objeto concreto particular y no de un análisis abstracto general basado en conceptos racionales. Por ende, esta iba a ser también la perspectiva que iba a adoptar Pasolini a la hora de construir su teoría audiovisual, especialmente cuando propone al cine como lengua escrita de la realidad, y también, como veremos en capítulos posteriores, es lo que iba a despertar el interés de Deleuze, ya que para él, el análisis del audiovisual debe surgir de una semiótica que parta de la observación de la imagen y no de una semiología de inspiración lingüística y conceptual.

La función del lenguaje pasoliniano es la de guiar al lector a través de la conciencia hasta una conciencia abolida, pasando por un estado pre-conciente, pre-simbólico, pre-histórico, donde hay una irracionalidad fuera del lenguaje, reino de los sueños y del mito, que para Pasolini encarnaba perfectamente el cine. Aún cuando construía sus artefactos provenientes de la alta cultura, citando a Baudelaire, Vivaldi o Masaccio, las citas estaban diseñadas para enfatizar la realidad primitiva que para él, por definición, permanece fuera de la historia y la cultura, ciertamente burguesas. Así también se explica la importancia que tendría el mundo mítico y ritual como celebración de un momento originario en la imaginación cinematográfica de Pasolini especialmente en el período de fines de la década del '60. Su interés por regresar a las fronteras entre el lenguaje y la realidad tenía el propósito de reformar las relaciones entre ellos, en la dirección de la conciencia y el conocimiento. Era un interés diametralmente opuesto a lo que él consideraba como la aceptación neorrealista de una transparencia absoluta entre la realidad y su representación, lo que para él implicaba una aceptación del mundo, no su comprensión. Pasolini buscó encontrar el lugar no donde el significado se disolvía, donde según su visión lo buscaba la vanguardia de su época, sino donde éste se generaba, en una etapa primitiva y mítica, donde lo social entraba, y donde la sociedad y lo simbólico nacían desde la realidad. Pasolini quería ser testigo de ese nacimiento, y en cada sentido del término, presenciarlo (Baranski, 1999, pp. 179). 


\section{El cineasta como intelectual orgánico}

Este cambio tan abrupto en las condiciones del contexto que lo circundaba, obligó a Pasolini no sólo a reformular nuevas estrategias poéticas sino que también le provocó una profunda crisis de identidad que lo llevó a replantearse su rol en aquella sociedad italiana en reestructuración. ¿Cuál sería entonces el nuevo papel del intelectual después de la caída de los ideales que habían forjado el modelo de la generación anterior? En un principio, para Pasolini como para la mayoría de los intelectuales italianos de izquierda de la posguerra, el concepto de intelectual como mediador entre las clases sociales fue el ejemplo a seguir, acatando esta acción social como si fuera un mandato. Este modelo era tomado del concepto de "intelectual orgánico", acuñado por Antonio Gramsci, que estaba dispuesto a salir de su torre de marfil para establecer vínculos orgánicos con la clase trabajadora. Siendo el vocero de los deseos y las necesidades profundas del pueblo, estos intelectuales serían instrumentales para crear una masa proletaria homogénea marcada por una ideología propia. Al nivel de la superestructura, esta nueva ideología o aparato hegemónico va a corresponder a nuevas relaciones de producción. Cambiando la estructura económica y la superestructura ideológica se posibilitaría el ascenso de lo que Gramsci denominó un nuevo "bloque histórico" que iba a pavimentar el camino para una revolución política. Por esta razón es que Gramsci exhortó una batalla cultural liderada por los intelectuales orgánicos y destinada a subvertir los valores de la ideología burguesa, para ser librada en ciertos terrenos: la escuela, los medios y las artes. Diseñada para alterar la manera en que el hombre piensa, esta batalla era especialmente crítica en Occidente donde los gobiernos dependen tanto de los consensos espontáneos como de la fuerza. Para los intelectuales comprometidos de la generación de Pasolini, esta batalla ideológica implicaba la creación de una nueva cultura "nacional popular". Esto refería a otro concepto gramsciano fundamental bastante preciso. Con "nacional", Gramsci no se refiera a la nación-estado, sino aquellos (especialmente la gente humilde) que comparten la misma historia y tradiciones. En cuanto que por "popular", a diferencia de muchos críticos marxianos, Gramsci no utiliza el término para denotar la representación de la clase trabajadora sino en un sentido más moderno del concepto de "cultura popular". Creía que si novelistas del siglo XIX como Eugenio Sue o Alejandro Dumas suscitaron un extenso interés popular, fue porque estos autores habían estado en contacto con corrientes profundas de la vida nacional popular. Teniendo sus raíces en el humus de la cultura popular, en contacto con una gran fibra nerviosa colectiva, estas novelas populares estaban en posición de descubrir creencias ocultas (las concepciones del mundo predominantes en las multitudes silenciosas) y hasta, algunas veces, ser capaces de difundir o crear nuevas ideologías. Con respecto a este último fenómeno, Gramsci observó que el concepto del "súper hombre" fue menos difundido por la alta cultura de Nietzsche que por las ampliamente leídas obras de Balzac y Dumas. Pero este concepto no se aplicaba solamente a la literatura popular sino también a los grandes exponentes como Shakespeare, Tolstoi o los autores griegos clásicos. Para que una obra posea un auténtico valor popular y artístico su belleza no sería suficiente, necesitaría tener también un contenido moral e intelectual que expresase de la forma más completa posible las aspiraciones más profundas de su público, esto es del ser nacional en cierta fase de su desarrollo histórico. La literatura debería ser al mismo tiempo un elemento con- 
temporáneo de la civilización a la que pertenece como una obra de arte (Green, 1990, pp. 54-55). En este caso esas mismas premisas podían aplicarse directamente a la producción cinematográfica.

El problema era que, con el avance implacable de la burguesía, el escenario fue cambiando enormemente, así como los ideales políticos y sociales de Gramsci parecían cada vez menos relevantes, este pensador se volvía menos determinante como presencia política comenzando a convertirse en un icono mítico y simbólico en las profundidades de la imaginación poética de Pasolini, quién en un reportaje realizado en aquella época declaró:

Me he distanciado de mi fase gramsciana porque objetivamente ya no tengo frente mío el mismo mundo que habitó Gramsci. ¿¿Si el pueblo dejara de existir, para quién serían narradas las historias nacionales populares? De ahora en adelante el pueblo y la burguesía se han fusionado dentro de una misma y única noción de masa. En realidad, ya no trabajo bajo el signo de Gramsci: mis films ya no son épicos líricos, nacionales-populares; se han convertido en algo más (Green, 1990, p. 87).

Ese "algo más" al que se refería Pasolini consistía en descubrir cómo continuar realizando un verdadero arte "nacional popular" cuando las condiciones del contexto habían cambiado de tal forma que ya no era posible identificar materialmente a través de la percepción a un sujeto concreto que encarne los ideales de las clases humildes y pueda oponerle una resistencia real al avance de la burguesía. El estado actual de las cosas no podía simplemente seguir siendo reproducido; necesitaba ser criticado. Después de 1948, la crítica era más abierta y mordaz, pero también desesperanzada. Había una nostalgia por algo aparentemente perdido para siempre. La idea de lo real había cambiado. Empezaba a ser asociado con los deseos y las fantasías, los cuales estaban en proporción directa con la imposibilidad de su concreción. Cuanto más horrible el mundo parecía, más fabuloso y desesperado era su "renunciamiento" y su deseo a escapar de él. La brecha abierta entre los sueños y la realidad se transformó, en el cine, en la brecha entre la ficción y la representación de la realidad. La realidad era vista como deslucida, vulgar e intolerable.

\section{Ruptura con la tradición}

Fue en Uccellaci e Uccellini (Pajarracos y pajaritos, 1966), su quinto largometraje de ficción, donde la desvinculación con la visión del mundo del marxismo ortodoxo sería plasmada de forma evidente, junto con su despedida y homenaje al Neorrealismo. Este film puede ser considerado como un documento sintomático de un momento crítico de la ideología marxiana. Un momento en el cual las esperanzas infundadas del pasado parecían como el preludio de un futuro incierto; para algunos, imposible. La secuencia paradigmática que ilustra este proceso es la del funeral de Palmiro Togliatti, co-fundador y líder del Partido Comunista italiano, fallecido en 1964. La muerte de este importante líder es evocada de forma elegíaca a través de la inclusión de imágenes documentales de archivo mostrando 
como una multitud llora ante el ataúd de Togliatti al son de las canciones de la Resistencia partisana. Pasolini se refirió a esta escena como "una unión solemne, grave, e infinitamente violenta entre la política y la muerte.” A pesar de que Pasolini nunca estuvo de acuerdo con el estilo político autoritario de Togliatti, él reconoció que el líder comunista había conducido al aguerrido partido en un momento cuando todavía estaba inspirado por los grandes ideales sociales de sus miembros, muchos de los cuales habían pasado tiempo en las prisiones fascistas y habían peleado como partisanos. Por ende, Pasolini vio la muerte de Togliatti como un símbolo tremendo de cambio: "La época histórica, la época de la resistencia, de las grandes esperanzas del comunismo, de la lucha de clases, ha culminado. Lo que tenemos ahora es el boom económico, el estado de bienestar, y la industrialización" (Stack, 1969).

Además, para Pasolini, Uccelacci e Uccellini era un film producto del cine mismo, y no de la cultura figurativa como lo fue Accatone (1961). Trata sobre el fin del Neorrealismo como una especie de limbo, y evoca al fantasma del Neorrealismo, particularmente el comienzo que muestra dos personajes viviendo su vida sin pensar en ella. Son dos típicos héroes del Neorrealismo, humildes, inocentes y rutinarios. Toda la primer parte del filmes una evocación del Neorrealismo, pero de un Neorrealismo natural e idealizado. "La era de Brecht $y$ Rosellini ha concluido" dice en un momento del film el cuervo marxista, uno de los personajes principales y representante simbólico del comunismo partisano en decadencia. Sobre este comentario Pasolini ha dicho:

con este comentario lo que quiero decir es que por un lado la era de la denuncia social y el gran drama ideológico característicos de Brecht y por el otro la denuncia del día a día característica del Neorrealismo, han terminado (Stack, 1969).

En otra entrevista realizada en la misma época, Pasolini se vuelve a referir a este cambio profundo que observa en su sociedad y cómo esta situación obliga a modificar el estilo representativo. Refriéndose otra vez al Neorrealismo declara:

Esa época ha concluido, y con ella, una visión del mundo. Italia, como el resto de Europa, y tal vez más rápido que el resto, ha dejado atrás el tiempo de la miseria y las privaciones características de la posguerra. La crítica de la vida cotidiana ya no es válida, por lo menos en la forma que uno encuentra en Paisa o La strada (Duflot, 1970).

Lo que estaba en juego detrás de esta frase y de esta actitud elegíaca ante el Neorrealismo no era la de abandonar el proyecto nacional popular gramsciano, el cual Pasolini nunca abandonaría hasta el final de su vida, sino por el contrario, habría que renovar sus formas para revitalizarlo, ya que ni la práctica del marxismo tradicional ni su estética oficial nacional como fue el Neorrealismo, seguían siendo eficaces frente a aquel escenario sociopolítico. Al director se le planteaba entonces un gran desafío estético y político que era nada menos que desarrollar una nueva poética que sea acorde a este nuevo proceso cultural por el que estuviera a la altura de los tiempos que corrían. 


\section{Hacia una nueva poética}

El origen de una nueva etapa en su carrera cinematográfica fue la respuesta a esta demanda en principio ideológica. Este nuevo período constará de cuatro films conocidos como el "cuarteto mítico" comenzando por Edipo Re (1967), seguido por Teorema (1968) y Porcile (1969) y culminando con Medea (1970), daba lugar a una etapa considerada por la mayoría de los críticos como la más críptica y compleja de su carrera como realizador cinematográfico. Si bien estos films en espíritu persiguen los mismos fines políticos que sus antecesores, sus procedimientos estilísticos muestran diferencias ostensibles. Pero este nuevo modo de hacer cine que Pasolini concibe en esta época no es de ninguna manera caprichoso sino que está supeditado a los numerosos cambios ya mencionados en los párrafos anteriores, tanto políticos como económicos que la Italia de la posguerra había sufrido con el avance de la cultura burguesa, corporizada en la sociedad de consumo del milagro económico de la década del '60. Al cambiar las condiciones de la realidad de forma tan abrupta era necesario modificar la estrategia retórica para que la resistencia a la homologación cultural pequeñoburguesa siguiera siendo eficaz.

Según la perspectiva de Pasolini, el pueblo rural que vivía fuera de la burguesía (el subproletariado como él mismo lo denominaría) y que hablaba en dialecto en vez de utilizar la lengua media italiana, el que también era considerado tanto por Pasolini como por una generación entera de intelectuales, como lo bueno y genuino, la verdadera reserva moral de la nación, estaba siendo destruida, convertidos en horribles pequeños burgueses por el crecimiento despiadado de los medios masivos y la sociedad de consumo capitalista. La desaparición del pueblo insinuada en Uccelacci e Uccellini indicó nada menos que el fin de la cultura nacional popular que tan profundamente ha influenciado al director italiano y a tantos otros de la generación de la posguerra. Esta desaparición del pueblo que tanto angustiaba a Pasolini al igual que a tantos otros intelectuales de la época, lo instó a buscar potencias en la imagen provenientes de las dimensiones míticas, a-históricas, que utilizaría como materia para la elaboración de un nuevo discurso estético desde donde comenzar a construir la resistencia ideológica. El Gramsci humano del proyecto nacional popular era finalmente reemplazado por su versión mítica retratada en la antología poética Las cenizas de Gramsci (1957).

La poética desarrollada en estos films, con sus rupturas estilísticas y sus choques expresivos, pone en escena las principales preocupaciones estéticas y existenciales que propulsaron las teorías cinematográficas de este autor durante la década del sesenta. Aquí, el salvajismo y el barbarismo, presentes en el corazón del cine, no sólo informan el hipotético monstruo irracional detrás de cada film, sino también a la narración misma, una narración propulsada por oscuros y salvajes impulsos que tienen origen tanto en el inconsciente de los individuos como en el pasado arcaico de la humanidad. La historia se rinde ante el mito como el tiempo lineal del Cristianismo para pasar a ser concebido como un eterno retorno ${ }^{2}$. Pasolini, en su fascinación por los mundos prehistóricos y mitológicos, en reiteradas oportunidades se refirió a la permanencia de los grandes mitos en la vida moderna (Green, 1990, p. 127). Este anhelo por las civilizaciones tradicionales parecía crecer en la medida en que iba creciendo la repulsión por la nueva Italia que se iba desarrollando a su alrededor. Para fines de la década del sesenta, él estaba convencido que las fuerzas nivela- 
doras de la burguesía consumista habían destruido las diferencias regionales (poblaciones, dialectos, modos de vida) que lo habían vinculado con su tierra nativa. Las civilizaciones imaginarias, bárbaras o arcaicas, visualizadas en sus films, eran concebidas como el polo opuesto al mundo moderno que él detestaba. En una entrevista, Pasolini declaró que:

Los bárbaros que yo retrato en mis films están siempre fuera de la historia, nunca son históricos. Los bárbaros en Medea (1970) son inventados. Los reconstruyo mediante la investigación etnológica y mi imaginación. En mis films, el barbarismo es siempre simbólico: representa el momento ideal de la humanidad (Green, 1990, p. 129).

Finalmente, para el director italiano, quien ha manifestado constantemente un amor y una pasión enardecida por la realidad, lo real es tal en tanto que permanece desintegrado y desarticulado ficcionalmente. Por ejemplo, un personaje realiza una mueca sin motivo, para nadie. Otro personaje sale de personaje para entrar en la realidad del actor con una abrupta carcajada inesperada, fuera de contexto. Y muchas veces también, los encuadres en sus films poseen características de desarticulación, como si no formaran parte de una estructura narrativa, y por sobre todo, no estuvieran articulados en un cauce narrativo significante. Esta desarticulación y desconexión entre el signo y el objeto son condiciones previas que para Pasolini determinan el estatuto de realidad. Si un gesto no posee un peso simbólico o conexión narrativa, sería por lo tanto irracional, una dosis de realidad pura sin diluir que no es funcional a ningún discurso. De esta manera la realidad es evocada al mismo tiempo que se asevera su pérdida. Lo que permanece en el film son los restos y fragmentos de una instancia de aparente plenitud y totalidad (Baranski, 1999, p. 176). Es por todas estas razones que, como habíamos anticipado al comienzo del artículo, la estrategia estética con la que Pasolini se apropió de la técnica audiovisual sigue estando hoy, por su profundidad filosófica y su amplio alcance como instancia integradora de dimensiones culturales, más vigente que nunca, y continúa teniendo un vastísimo potencial de desarrollo para la configuración de nuevas prácticas discursivas para el siglo 21 .

\section{Notas}

1. En el ensayo de Paul Ginsborg "Familly, Culture and Politics in Contemporary Italy", primera inclusión en la compilación Baranski, Zygmunt G. and Robert Lumley (eds.). Culture and Conflict in Postwar Italy. Hong Kong: The Macmillan Press Ltd., 1990, se pueden encontrar datos concretos y muy significativos que referencian el cambio en los índices de la economía y en el standard de vida de la población italiana durante el denominado "Milagro económico" y sobre todo en su período de eclosión considerado entre los años 1958 y 1963. Los datos más elocuentes con respecto a este fenómeno se pueden encontrar en la sección intitulada "The great transformation" dentro del mismo ensayo que va desde la página 32 hasta la 36.

2. Concepto utilizado por Mircea Eliade (1907-1986), etnólogo rumano especialista en 
mitología de gran influencia en el pensamiento de Pasolini en aquella época, para designar la temporalidad circular característica de la civilizaciones primitivas. Ademas de Eliade, otros antropólogos que también tuvieron una fuerte presencia en el imaginario de Pasolini fueron Lucien Lévy-Bruhl y Sir James George Frazer.

\section{Referencias Bibliográficas}

Duflot, J. Conversaciones con Pier Paolo Pasolini. Traducción: Joaquín Jordá. Barcelona: Editorial Anagrama, 1970. Pág. 46.

Foucault, M. ¿What is an author? (1969) en Adams, H. y Searle, L. (1966). Critical Theory since 1965. Tallahassee: Florida State UP, pp. 138-48.

Green,N.(1990).PierPaolo Pasolini:Cinemaas Heresy. Princeton:Princeton University Press. Mariniello, S. (1999). Pier Paolo Pasolini. España: Ediciones Cátedra S.A. p. 320. pp. 54-55. Pasolini, P. P. (1997). Cartas Luteranas. Traducido por Torrell, J; Giménez Merino, A. y Capella, J, R. Madrid: Editorial Trotta, p. 12.

(1993). Escritos Corsarios. Traducido por Silvia Manteiga, Santiago de Compostela: Edicions Positivas, p. 119. Acto seguido Pasolini aclara que su tesis no es completamente herética o heterodoxa sino que en el Manifiesto comunista de Marx ya se mencionaba un genocidio cultural cometido por la burguesía contra poblaciones subproletarias y coloniales.

(1982a). Empirismo Hereje. Traducido por Miguel Serras Pereira. Lisboa: Assirio e Alvim. pp. 127-8.

(1982b). Hipoteses de Laboratorio en Empirismo hereje. Traducido por Miguel Serras Pereira. Lisboa: Assirio e Alvim. p. 58.

(1982c). O fim da Vanguarda, en Empirismo hereje. Traducido por Miguel Serras Pereira. Lisboa: Assirio e Alvim, p. 100.

Pasolini, Entrevista con Michel Maingois, Zoom (Octubre 1974), pág. 24, citada por Green, N. (1990), p. 129.

Pasolini, Entrevista con Gian Piero Brunetta, Cahiers du Cinema. No 212 (May 1969), p. 15, citado en Green, N. (1990). Pier Paolo Pasolini: Cinema as Heresy. Princeton: Princeton University Press, p. 87.

Rohdie, S. Neo-Realism and Pasolini: the desire for reality. En Baranski, Z. G. (ed.) (1999). Pasolini Old and New. Dublin: Foundation for Italian Studies: University College Dublin. pp. 164-179.

Stack, O. (1969). Pasolini on Pasolini. Bloomington: Indiana University Press. pp. 105-06. 
Summary: The central problem of the paper is the shaping of visual sign language in the context of an imaginary dialogue between the perspectives that Pier Paolo Pasolini and Gilles Deleuze, in his writings Heretical Empiricism and the time-image respectively, developed on this topic.

First, what the French philosopher claimed on Pasolini 's theory is that (unlike Metz, Eco, Garroni and other contemporary semioticians in the early ' 60 s, who have attacked the author accusing him of lack of professionalism and semiotics ingenuity) the narrative is not a manifest data of cinematographic images, but was historically acquired. This is precisely because both authors (and this is perhaps its central theoretical coincidence) consider that the film image can not be assimilated or reduced to a statement .

That's why, given that advances in technology and the proliferation of formats, genres, production and distribution channels propose increasingly numerous and deep analytical challenges, to retrieve and to analyze fully the implications of this theoretical perspective, can generate a large contribution to contemporary studies of audiovisual languages.

Key words: audiovisual - Felix Guatari - film - flows - Gilles Deleuze - Henri Bergson - neomaterialism - Pier Paolo Pasolini - poststructuralism - representation - Semiotics significance - subjectivity.

Resumo: O problema central do artigo é a conformação lingüística do signo audiovisual no contexto de um diálogo imaginário entre as perspectivas que Píer Paolo Pasolini y Gilles Deleuze, nos seus escritos Empirismo Herético e A imagem - tempo respectivamente, desenvolvem sobre essa temática.

No primeiro lugar, o que o filósofo francês reivindica sobre a teoria de Pasolini é que a narração não é um dato manifesto das imagens cinematográficas em geral, senão que foi historicamente adquirida. Isto é porque os autores consideram que a imagem cinematográfica não pode ser assimilada nem reduzida a um enunciado.

É por isso que tendo em conta que os avances tecnológicos e a proliferação de formatos, gêneros, canais de produção e distribuição propõem desafios analíticos cada vez mais numerosos e profundos, recuperar e analisar as conseqüências desta perspectiva teórica, pode gerar um grande aporte nos estudos contemporâneos das linguagens audiovisuais.

Palavras chave: audiovisual - cinema - Félix Guatari - fluxos - Gilles Deleuze - Henri Bergson - neo-materialismo - Pier Paolo Pasolini - pos-estructuralismo - representação semiótica - significação - subjetividade. 